\title{
Trazado y construcción de arquerías en los inicios del gótico andaluz. Estudio del caso cordobés
}

\author{
Tracing and construction of arcades in the early Andalusian \\ Gothic. A study of Cordovan case
}

\author{
A. J. García-Ortega ${ }^{*}$
}

RESUMEN

Las arcadas góticas de las iglesias parroquiales cordobesas están entre las primeras levantadas en Andalucía. Sus características y afinidades permiten un amplio estudio sobre su diseño, trazado y medida, construcción, etc., a la vez que sugieren la hipótesis de que todos estos aspectos pudieron obedecer a unos mismos criterios preestablecidos.

La investigación realizada lo corrobora, comprobando cómo derivaban en secciones resistentes que los maestros góticos consideraban válidas dentro de un rango de luces y cargas, aprovechando un sobredimensionamiento estructural del que apenas eran conscientes. Esto redundaba en una gran eficacia constructiva, demostrando su confianza en el oficio, aunque contradecía ciertos criterios de proporcionalidad al uso. En el proceso de diseño intervenía, determinantemente, el patrón métrico establecido para el edificio, generando las dimensiones fundamentales. Entre ellas estaban los radios de curvatura de los arcos, que se homogeneizaban para permitir la reutilización de cimbras y plantillas, la estandarización de dovelas, etc.

$173-2$

Palabras clave: Córdoba; arcada; Gótico; trazado; reglas.

\section{SUMMARY}

The Gothic arcades of the Cordovan parishes are among the earliest in Andalusia. Their design, tracing, measure and construction can be studied thanks to their characteristics and affinities, while at the same time suggest that they follow the same preset criteria.

The present work demonstrates the existence of preset criteria, which determined resistant sections that the Gothic masters considered suitable within certain margins. In fact they were using a structural oversizing, of which they were barely aware. This approach was constructively very efficient, showing the masters' confidence in their craft, but it contravened the proportionality criteria of the time. In the design process, the masters used the metrical pattern established for the building to generate the main dimensions. Among these dimensions was the radius of curvature, which was often invariant to enable reuse of formwork and templates, the standardization of dowels, etc.

Keywords: Córdoba; arcade; Gothic; tracing; rules.

\footnotetext{
(*) Escuela Técnica Superior de Arquitectura. Universidad de Sevilla (España). Persona de contacto/Corresponding author: agarcia11@us.es (A. J. García-Ortega).
}

Recibido/Received: 25 aug 2011 Aceptado/Accepted: 13 sep 2011 Publicado online/ Published online: 12 jun 2012 
1. Esquema tipo de parroquia gótica andaluza (S. Lorenzo, Córdoba, s. XIII): planta y secciones longitudinal y transversal (restitución eliminando añadidos y reformas posteriores del edificio original).

2. Iglesia parroquial de San Lorenzo, vista desde el norte.

3. Plantas a la misma escala de las primeras iglesias parroquiales de Córdoba (restitución omitiendo añadidos). De izquierda a derecha: San Lorenzo, San Pedro, Santa Marina, La Magdalena y Santiago.
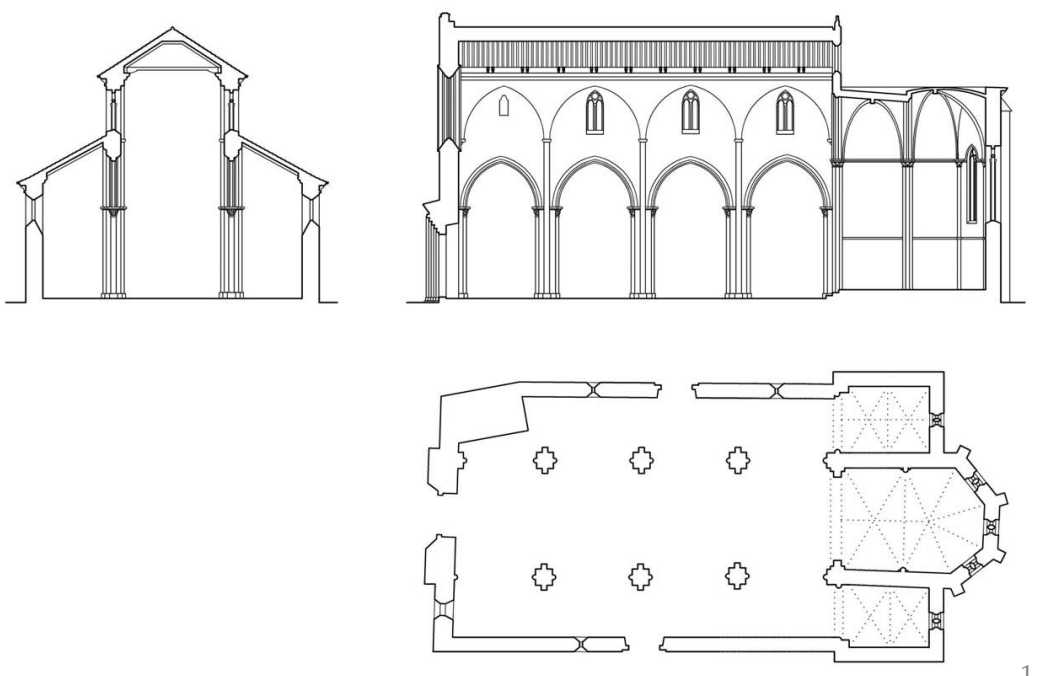

Tipológicamente se adoptó el modelo de cabecera abovedada, frecuentemente triabsidiada, y cuerpo basilical de tres naves, con la central más ancha y alta; las mismas se formalizaban mediante dos líneas de arcadas sosteniendo cubiertas de madera, lo que reducía costes y tiempos de ejecución (Figura 1). Estas arcadas, aun

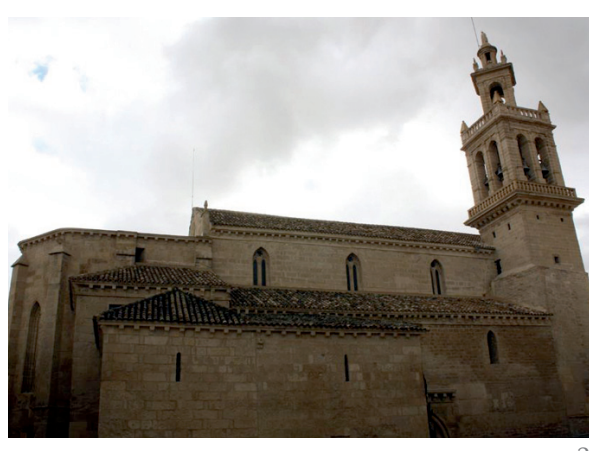

partiendo de masivos esquemas formales de ascendencia románica, se estilizarán verticalmente para obtener una espacialidad más gótica. Pese esto, y al poco peso de la solución de cubierta, el sistema estructural ha demostrado a lo largo del tiempo su gran estabilidad.

Sobre este tipo de arquerías, frecuente en el gótico bajomedieval andaluz, es posible realizar una investigación en el conjunto parroquial cordobés, el más amplio y mejor conservado del sur peninsular, además de uno de los más tempranos. En Córdoba aún subsisten cinco iglesias, presumiblemente coetáneas, con características formales y constructivas similares, y todas localizadas en la Ajerquía, el sector oriental de la ciudad: San Lorenzo (Figura 2), San Pedro, Santa Marina, La Magdalena y Santiago (Figura 3). Otras cuatro parroquias no han llegado hasta nuestros días, y el resto se inician tardíamente o bien reaprovecharon dilatadamente antiguas mezquitas (Figura 4).

Aunque existen trabajos sobre los abovedamientos absidiales de este tipo de iglesias (1), las cubiertas de madera de las naves (2), su sistema mural (3), o sobre el trazado de la planta (4), todavía falta una investigación amplia y sistemática sobre sus arcadas góticas, fundamentales en la conformación y construcción de los edificios. Constituyen además, junto con las bóvedas, el elemento estructural más atrevido, y en el que es clara-
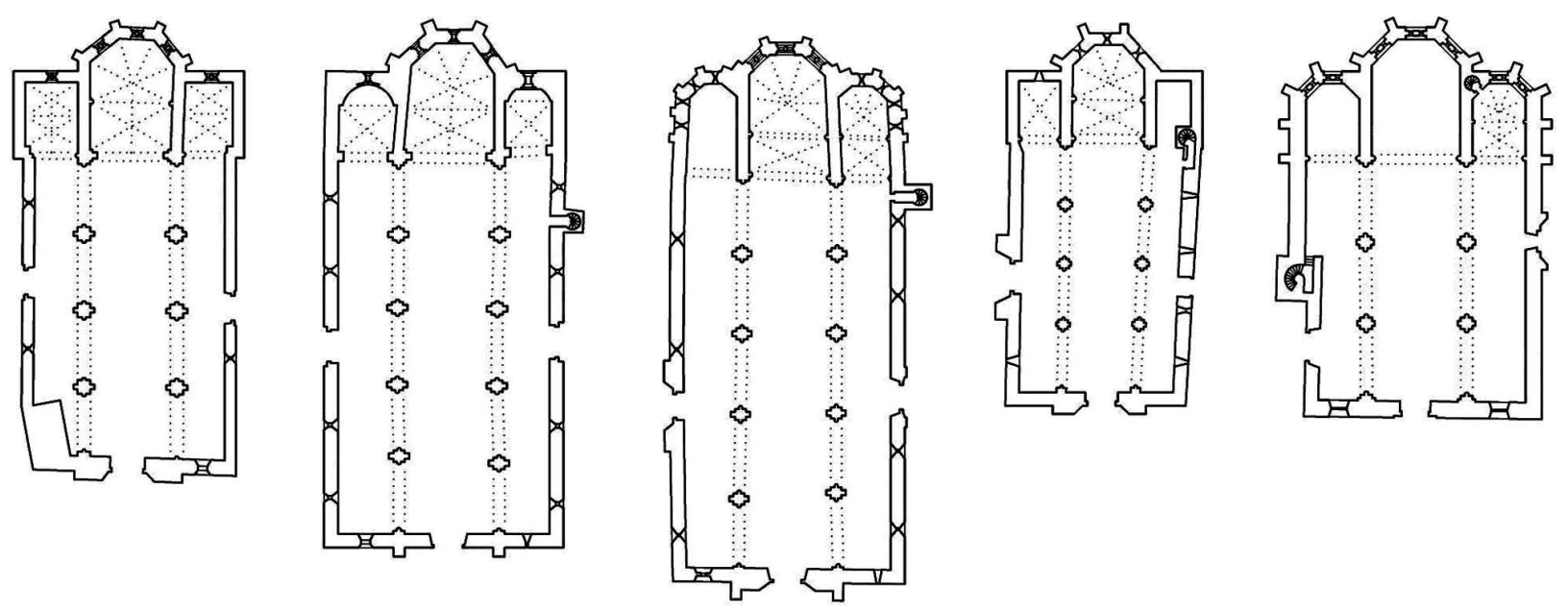
mente conveniente una sistematización y optimización de su trazado y construcción; esto redundaría en despieces estandarizados y homogéneos (sillares, dovelas, plantillas...), y también en un mejor aprovechamiento de medios auxiliares como las cimbras.

Dadas las grandes similitudes formales de las cinco edificios seleccionados, cabe la hipótesis de que sus arquerías se diseñaran atendiendo a unas mismas reglas preestablecidas, que responderían a la necesaria estandarización de estos elementos. Para su estudio se realiza un análisis de los aspectos dimensionales, geométricos y de trazado, considerando también el vínculo con las soluciones estructurales y constructivas aplicadas; éstas últimas son a menudo evidentes en los propios paramentos de sillería libres de revestimientos. También se cuenta con los datos documentales de las frecuentes intervenciones de época reciente, algunos recogidos en expedientes oficiales inéditos (6), las inspecciones que han posibilitados ciertos derrumbes, y el seguimiento gráfico que el autor ha realizado durante los últimos años (Figura 5).

Incluso, trascendiendo de las particularidades del caso estudiado, esta investigación pretende contribuir a la detección del modus operandi medieval, profundizando en unos conocimientos del oficio decantados a lo largo de siglos, y de los que aún nos falta mucho por conocer. En este sentido debe advertirse que el diseño histórico de arcos, bóvedas o cúpulas ha sido poco investigado, ante el infundado convencimiento de que el proceder medieval era esencialmente incorrecto por su carencia de fundamentos científicos. A esto se añade la dificultad intrínseca de un estudio a posteriori, algo para lo que los edificios seleccionados suponen una inapreciable oportunidad por sus manifiestas semejanzas arquitectónicas y las coincidencias espacio-temporales.

\section{CONTEXTO Y BASES DE ANÁLISIS}

La investigación planteada no trata de "comprobar" las arquerías con los conocimientos y herramientas de cálculo estructural actuales. El objetivo, más bien, es detectar las claves proyectuales (diseño y trazado, dimensión, construcción...) utilizadas por los propios maestros góticos. Por ello las hipótesis que se formulen deberán asumir su escasa formación teórica. También debemos tener en cuenta el desconocimiento medieval de las leyes de la estática estructural y la resistencia de materiales, careciéndose incluso de una idea clara del propio concepto de fuerza, su línea de acción, o su composición mediante el paralelogramo de fuerzas (5).

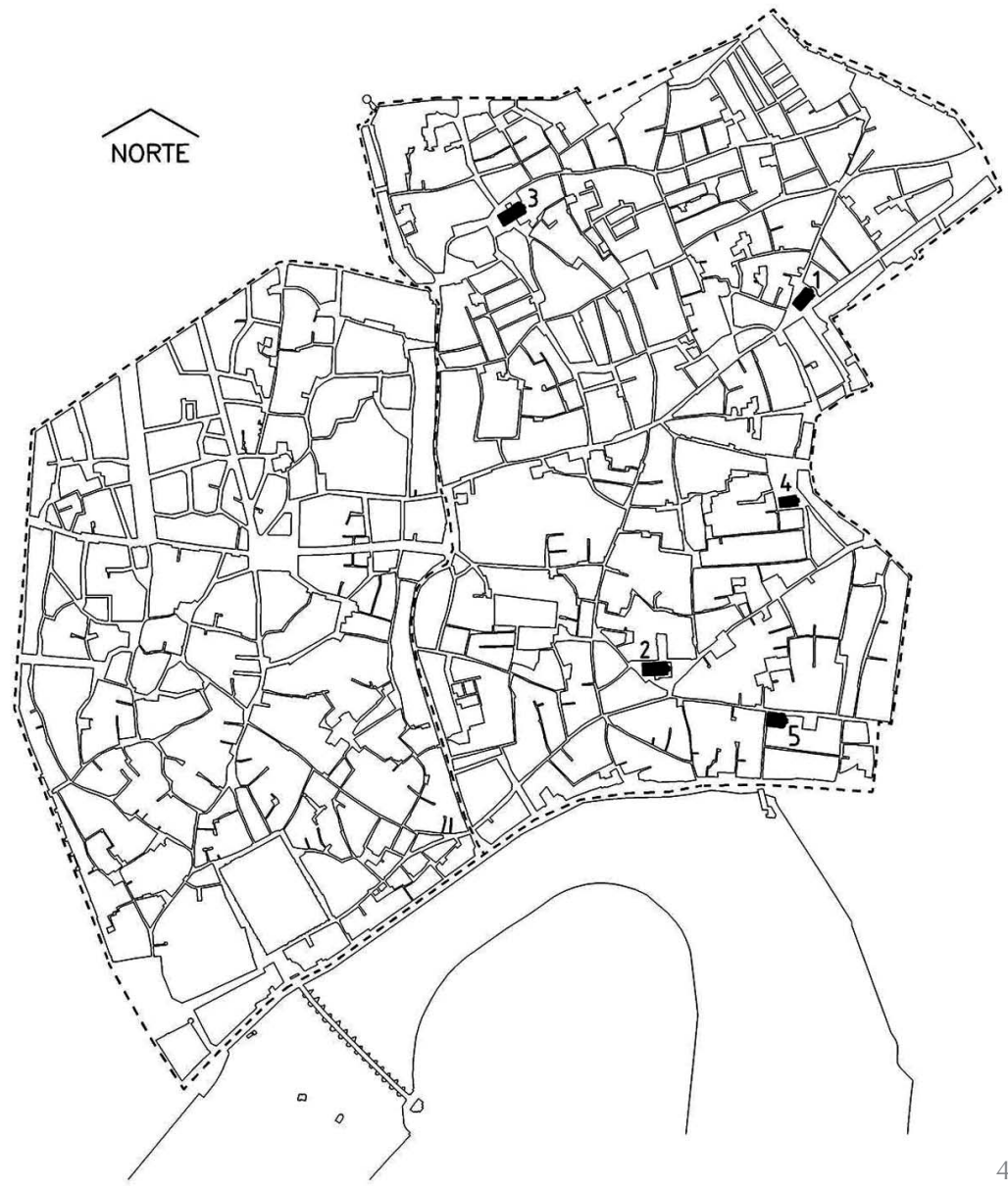

Sin embargo, como precisa Escrig (6), esto no significa que la construcción de "miles de iglesias y catedrales góticas se convirtieran en un ejercicio de cálculo y riesgo, y del mismo modo que la cantería tenía sus reglas transmitidas sin trascender del gremio, el dimensionamiento también los tuvo, reglas que no era conveniente transgredir y que daban coeficientes de seguridad suficientes...". Estas reglas, según Heyman (7), fueron desarrolladas, perfeccionadas y lentamente codificadas principalmente a lo largo de los siglos XII y XIII, derivando en lo que podríamos denominar una estática empírica. Ésta marcaba los límites fiables de las posibilidades en los diseños, resolubles con distintos procedimientos numéricos y geométricos (8). A nivel gráfico se manejaban irreflexivamente trazados geométricos, desconociendo sus fundamentos últimos en las reglas numéricas se operaba con valores sencillos y bajos, y que solían implicar relaciones y proporciones de larga tradición en la arquitectura $(1 / 1,5 ; 2 / 3 ; 1 / 2 ; 1 / 3)$.

Estos recursos se podían aplicar en conjunción a un patrón dimensional establecido específicamente para el edificio, plasmado según Bechmann (9) en una vara de medir o virga. Esto permitía, entre otras cosas, dar tamaño a multitud de esquemas adimensionales al uso, útiles para el trazado general
4. Sectores urbanos de Córdoba: Villa (izqda.) y Ajerquía (dcha.). Iglesias parroquiales estudiadas: 1. San Lorenzo, 2. San Pedro, 3. Sta. Marina, 4. La Magdalena, 5. Santiago.

5. Derrumbe de La Magdalena (1990). Archivo de la Junta de Andalucía.

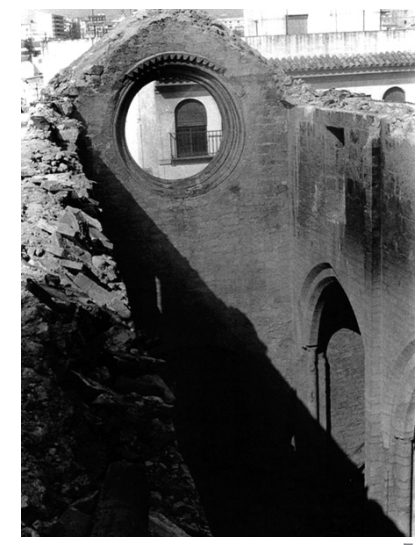


6. Submúltiplos de varas medievales y mayoración gráfica por raíz de dos. del organismo arquitectónico, el diseño de elementos formales o estructurales, etc. Se trata de un proceder recogido en distintos tratados tardogóticos alemanes, aunque en ellos el módulo suele ser el espesor del muro del presbiterio (10). Otras veces se utilizaba el sistema metrológico al uso en el lugar, lo que facilitaba operaciones elementales a través de los múltiplos y submúltiplos preestablecidos de la vara (11). Entre éstos últimos, es frecuente su mayoración por raíz de dos, fácilmente determinable con trazados geométricos (diagonal del cuadrado) o relaciones numéricas aproximadas e inmediatas, como la 7/5 de Lechler (12) (Figura 6).

Concretamente en las iglesias cordobesas de San Lorenzo, San Pedro, Santa Marina y Santiago se ha demostrado la adopción de la vara de Burgos $(83,59$ cm.) como módulo dimensional (13). En La Magdalena no se detecta un uso expreso de esta unidad, aunque al tratarse de un edificio sustancialmente más pequeño en todos sus miembros, pudo recurrirse a un submúltiplo de la misma, el paso $(69,66 \mathrm{~cm}$.). Esta hipótesis va a permitir explicar sus arquerías con los mismos criterios que el resto.

En el proceso de diseño operaba, en definitiva, un principio de semejanza o proporcionalidad, que establecía que la validez de una forma estructural continúa siendo válida independientemente de su tamaño; esto, a efectos prácticos, conducía a estructuras geométricamente similares en edificios de un amplio rango dimensional. Este proceder, irreflexivo, estaba equivocado en sus fundamentos, según demostraría Galileo en su ley de cuadrado-cubo. Su principal consecuencia es que en estructuras sometidas principalmente al peso propio, la tensión crece linealmente con el tamaño; si ésta se quiere mantener constante en un valor admisible, los elementos deberían regruesarse al crecer la estructura.

Sin embargo esta problemática ha sido exhaustivamente analizada por autores como Huerta (14), demostrando que el principio de semejanza conducía a resultados aceptables y seguros para las luces y cargas de la mayoría de las obras de fábrica históricas. Dado que las tensiones de trabajo son bajas, como señala Heyman (15), el problema de la resistencia no es significativo; son más restrictivos los requisitos de equilibrio, dependientes de la forma de la estructura, su geometría y la proporción de cada miembro en sí y en relación al conjunto.

Concretamente, en el dimensionamiento de los pilares se atendía principalmente a su sección típica, el fuste, obviando aspectos formales como basas, molduras, etc.; tam- bién, consecuentemente sus cimentaciones se entenderían como un recrecido o retallo del elemento que reciben, una simple ampliación de su base. Se trata de un criterio bien documentado luego en el tardogótico español; por ejemplo, el maestro Enrique refrenda así la dimensión dada en la traza a los pilares de la catedral de Segovia: "...treze pies de grueso en el byvo syn la salida de las sotobasas" (16). Por ello, en nuestro trabajo el análisis de los pilares parte de la medición y dibujo de la sección del fuste, con especial interés en el núcleo sensiblemente cuadrado resultante de descontar las semicolumnas y pilastras. También interesan las luces de los arcos que sustentan y la propia altura de los elementos, dimensiones que inciden en parámetros como la esbeltez o la relación entre espesor del elemento y la luz a salvar.

La cota de coronación del pilar constituía un nuevo plano de trabajo en la erección de la fábrica, sirviendo de referencia para el trazado de las arcadas (17). El saliente de los ábacos o cornisas era un apoyo idóneo para los andamiajes y cimbras, imprescindibles en la ejecución de esta parte del organismo arquitectónico. Aunque los arcos tienen un dovelaje, esto constituye una solución intrínsecamente formal y constructiva; la sillería superior del gran muro de la arcada tiene por sí misma gran estabilidad y capacidad portante para comportarse como un gran arco rebajado, algo frecuente en las estructuras góticas merced a los rellenos del trasdós (18). Esto, por ende, resta importancia al estudio de las posibles líneas de empujes, difíciles de determinar con certeza en un arco como advierte Huerta (19), y cuyas posiciones nunca llegarían a desestabilizar el conjunto de la arcada; incluso, las fisuras propias del comportamiento estructural de un arco no se evidencian en la gran mayoría de los casos analizados.

Por todo ello, el interés principal está en la geometría y trazado del perfil apuntado de los arcos, así como su modulación dimensional en base al patrón métrico del edificio. Tal y como se ha podido verificar por Carrasco y Millán (20) en el gótico catalán, por su problemática específica el arco apuntado es un sistema formal con gran autonomía del resto de la fábrica, atendiendo a reglas propias para resolver su diseño (luz, flecha, radio...) y construcción. Para ello se contaba con soluciones preestablecidas que las tipificaban, aprendidas en el seno del oficio, como demuestra el conocido Álbum de Villard (21). En este manuscrito del siglo XIII se recogen algunos esquemas geométricos que resuelven el diseño del arco y sus dovelas; el trazado y corte de éstas se realizaba con auxilio de escuadras, dibujadas por el propio Villard (fol. 21) (22). Posteriormente, para su coloca- 
ción en el arco se atirantaba su lecho de contacto con la anterior uniéndose con el centro (sabemos que el término tirantez era usado entre los canteros (23); por ello era conveniente que dicho centro estuviera comprendido dentro de la luz libre del arco, desaconsejándose arcos excesivamente apuntados.

\section{FORMALIZACIÓN ARQUITECTÓNICA DEL CUERPO DE NAVES}

El cuerpo de naves de estas iglesias se formaliza como un gran cajón mural, dividido por dos líneas de arquerías apuntadas, que aprovechan la mayor altura de la nave central respecto a las laterales para introducir huecos de iluminación, frecuentemente del tipo de rosa y mainel. Estas arquerías tienen un fuerte entendimiento longitudinal, sin la sectorización que hubiera supuesto la cubrición con tramos de bóvedas, sustituidas por una larga e indiferenciada techumbre de madera. Esta es de par y nudillo en la nave central y de faldón único en las laterales, sirviendo ambas de arriostramiento superior de las arcadas y los muros perimetrales (Figura 7).

Para las arquerías se utiliza un doble nivel de arcos. El inferior salva la luz entre soportes, y el superior mejora la estabilidad lateral, a la vez que aumenta el espesor para recibir la cubierta. Esta formalización se inspira en la del muro armado románico, utilizado por ejemplo en el templo monacal de Poblet (Figura 8), aunque sobre el modelo se practicaron, con habilidad, importantes adaptaciones formales. Entre lo más destacable estaría el apuntamiento del doble nivel de los arcos, que aunque no muy acentuado, conlleva las ventajas del arco gótico: se resuelven distintos luces o alturas de clave con un mismo radio de curvatura, permitiendo el mismo tipo de dovela y la reutilización de las cimbras, unos aspectos determinantes en la economía y sistematización de la ejecución de estos elementos.

Aprovechando la sustancial reducción de pesos y empujes, todo el organismo arquitectónico se adelgaza, adquiriendo mayor esbeltez. Igualmente, en la composición del alzado desaparecen las compartimentaciones horizontales y los elaborados desarrollos en profundidad de los huecos, que devienen en simples abocinamientos. Todo esto le aportará a las arquerías cierto carácter gótico, aunque la carencia de fasciculados o molduras en pilares y arcos delatará todavía su origen; también es Ilamativa en este sentido, la austeridad de la sección del perfil del arco, recta y tan sólo con achaflanamientos de sus aristas.

La sucesión de arcos tiene garantizada la absorción de sus empujes: en los pies en- tregan en el gran hastial de la fachada principal, un masivo muro dotado a veces de pequeños contrafuertes para enmarcar la portada; y en la cabecera enlazan con los largos lienzos separadores de las capillas absidiales. En ambos casos se utiliza como articulación formal unos responsiones, consistentes en una pilastra y una semicolumna adosada, y que vienen a equivaler prácticamente a la mitad de un pilar; sólo excepcionalmente se sustituyen por ménsulas o columnas colgadas al modo cisterciense, quizás fruto de reformas posteriores.

Los arcos se soportan en pilares, retrasados para su época, constituidos por un núcleo cuadrangular con columnas en la dirección del pórtico y pilastras en la otra, que mejoran sustancialmente la estabilidad y comportamiento mecánico en la dirección transversal del pórtico (Figura 9). Dichas pilastras, ante la inexistencia de arcos fajones, pueden ascender a lo largo del fuste y el muro hasta enlazar con la arcada superior, con una pequeña imposta de transición. Las columnas asumen la altura del pilar, constituyendo el orden arquitectónico en el que apoya el arco apuntado; éste arranca de capiteles con decoraciones vegetales, rematados por delgados ábacos que sólo a veces se continúan a modo de listel en todo el núcleo cuadrado. El conjunto del fuste tiene basas compuestas de toro y escocia sobre plinto, en ocasiones sustituidas por simples pedestales prismáticos.

\section{RESOLUCIÓN CONSTRUCTIVA DE LAS ARQUERÍAS}

La piedra es el material preponderante en las iglesias y de manera exclusiva en las arquerías estudiadas. Desde tiempo inmemorial, en la ciudad se utilizó la biocalcarenita marina del Mioceno Superior, extraída de las cercanas canteras de las estribaciones de Sierra Morena. Tiene gran facilidad de extracción, corte y labra, un peso específico rondando los $24 \mathrm{KNw} / \mathrm{m}^{3}$; sus resistencias son heterogéneas y relativamente bajas (7-20 Nw/mm²), debido a su gran porosidad (superior al $15 \%$ ) y a la inclusión de fósiles de gran tamaño, descendiendo hasta los $2,5 \mathrm{Nw} / \mathrm{mm}^{2}$ cuando se satura de agua (24). Todas estas características han hecho que el material, una vez colocado en las fábricas, se erosione y degrade con facilidad.

Salvo en La Magdalena, con despiece convencional de juntas verticales alternantes, en el resto de los edificios los sillares se aparejan a soga y tizón único, una solución, de larga tradición local (25). Las piezas son prismáticas, y de proporciones muy alargadas (ancho/alto/largo de relación 1/2/4-5), propias de piedras más duras, si atendemos a la tratadística tardía (26). En los paramen-
7. Arcada norte de San Lorenzo (ss. XIII-XIV)

8. Arcada norte en la iglesia cisterciense del monasterio de Poblet (s. XII)

9. Detalle de pilar de San Lorenzo.
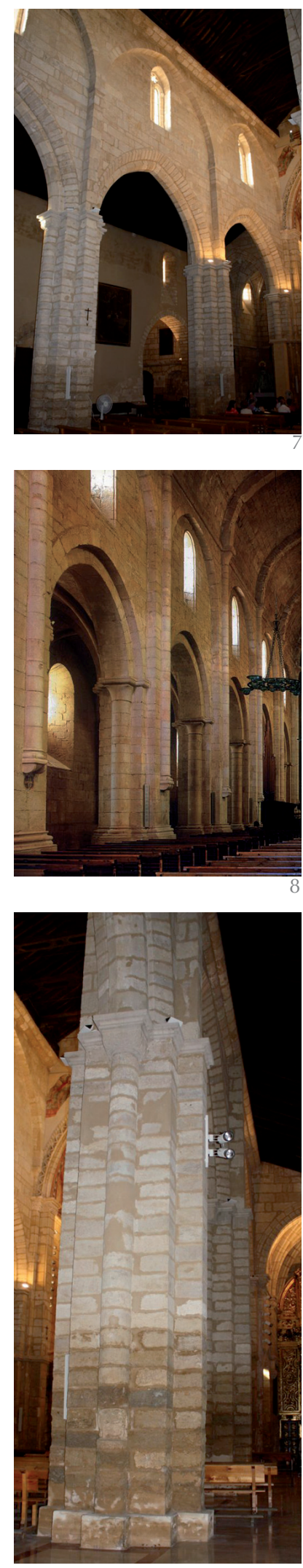
10. Paramento de Santa Marina: sillar a tizón y juntas con mortero de cal y guijarros.

11. Arcada norte de Santiago tras su derrumbe (1988). Archivo de la Junta de Andalucía.

12. Paramento a soga y tizón y despiece de arco con doble rosca adovelada y clave formada por dos piezas simétricas (San Pedro).

13. Sección constructiva de la arcada: cimiento, pilar, arco, muro superior y encuentros con cubiertas.

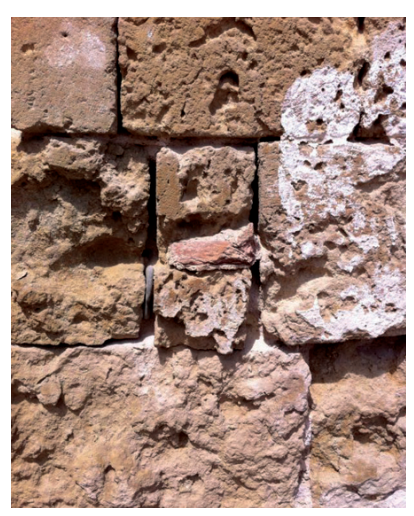

10

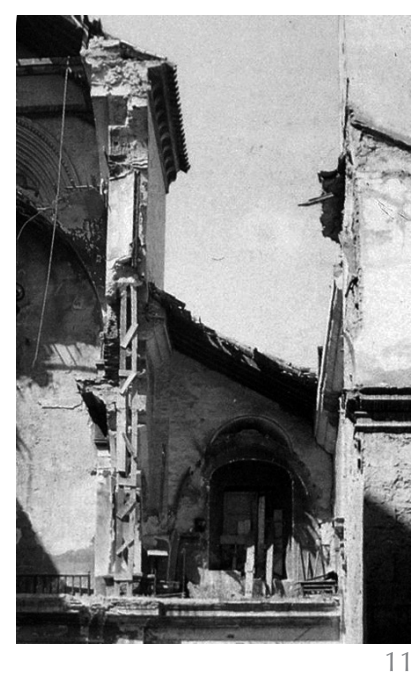

tos superiores de las arquerías, la soga alcanza fácilmente los 100-110 cm. (oscilando en un intervalo entre 78 y $113 \mathrm{~cm}$.), con tizones de 20-21 cm. (intervalo 17-30 cm.) y con alturas de la pieza (y de hilada) de 40-41 cm. (intervalo 32-43 cm.). Para este rango dimensional, los sillares de los lienzos murales tendrían un peso alrededor de $230 \mathrm{Kp}$ (intervalo 100-350 Kp), descendiendo hasta incluso la mitad en muchas piezas de los pilares o en las dovelas de los arcos.

Aunque se extraería y tallaría piedra para elementos singulares del catálogo formal gótico (basas, molduras, capiteles, etc.), muchos de los sillares de las arcadas provendrían del expolio de los edificios islámicos (27). Posteriormente, a pie de obra, se realizaría un ajuste de las piezas, como han demostrado los trabajos arqueológicos de Marfil, que han hallado picaduras de arenisca bajo el pavimento de San Pedro (28) y La Magdalena (29). Las piezas se colocaban en la fábrica sobre un fino lecho de mortero de cal, que frecuentemente no supera el centímetro; tanto en las juntas horizontales como verticales se introducen a menudo guijarros de río con forma de laja, fragmentos de ladrillo o trozos de teja (Figura 10). Las dosificaciones de los morteros no superan la relación 1:1 entre cal y arena; incluso, algunos estudios han detectado adiciones de picadura de piedra o ladrillo, aportándoles tonos, amarillentos, rosados o parduzcos (30).

Los derrumbes sufridos por las iglesias de Santiago (año 1988) (31) o La Magdalena (año 1990) (32), con posteriores reconstrucciones, y las catas y obras de emergencia en S. Pedro (33), han permitido conocer la sección constructiva de los arcos. Ésta evidencia la habilidad del maestro gótico para resolver con un delgado muro de tres hojas la estabilidad y capacidad portante del elemento, y su adecuada articulación formal y material con el resto del organismo arquitectónico, como la cubierta a media altura de la nave lateral (Figura 11).

Los arcos superiores son muy sencillos, con dovelas prismáticas cuyas juntas son perpendiculares al intradós; formalmente parecen como adosados al muro, aunque las hiladas horizontales de sillería efectúan la traba con el conjunto de la arquería. Los arcos inferiores son más elaborados, materializándose como dos roscas adoveladas, con despiece autónomo entre ellas, y de sección decreciente hacia el intradós. Las dos ramas del arco apuntado cierran en la clave, una pieza especial que a menudo presenta un tamaño desigual o asimétrico, fruto de la necesidad de resolver un encuentro deficiente por errores de ejecu- ción. Esta clave la encontramos tanto formada por una única pieza, como por dos simétricas con lecho de contacto en el eje de simetría del arco. Ambas soluciones son frecuentes en la construcción de la época, como estudió Branner (34) (Figura 12).

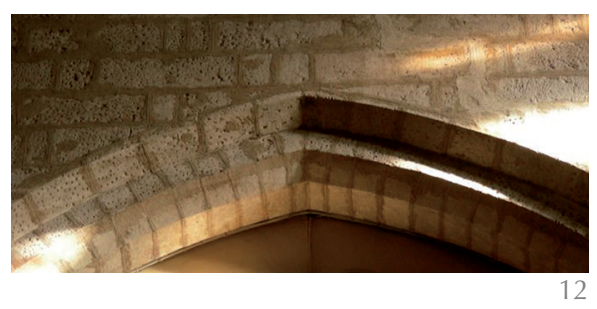

En estos arcos van entregando las sucesivas hiladas del gran muro de la arcada. Éste constructivamente se resuelve con dos paramentos de sillería despiezados a soga y tizón, y un relleno interior de mampostería; se está secundando, pues, la solución que ha sido detectada de manera sistemática en el resto de los muros del edificio (35). Sin embargo, gracias al menor espesor de las arcadas (90$100 \mathrm{~cm}$.) frente a éstos (125-140 cm.), los tizones pueden ser totalmente pasantes, ligando las dos hojas exteriores; éstas también se adelgazan respecto a las utilizadas en los muros, constituidas ahora por un único sillar en vez de dos pareados (Figura 13).

Los pilares están constituidos por un núcleo cuadrangular de sillares de arenisca labrados exclusivamente al exterior, alojando un

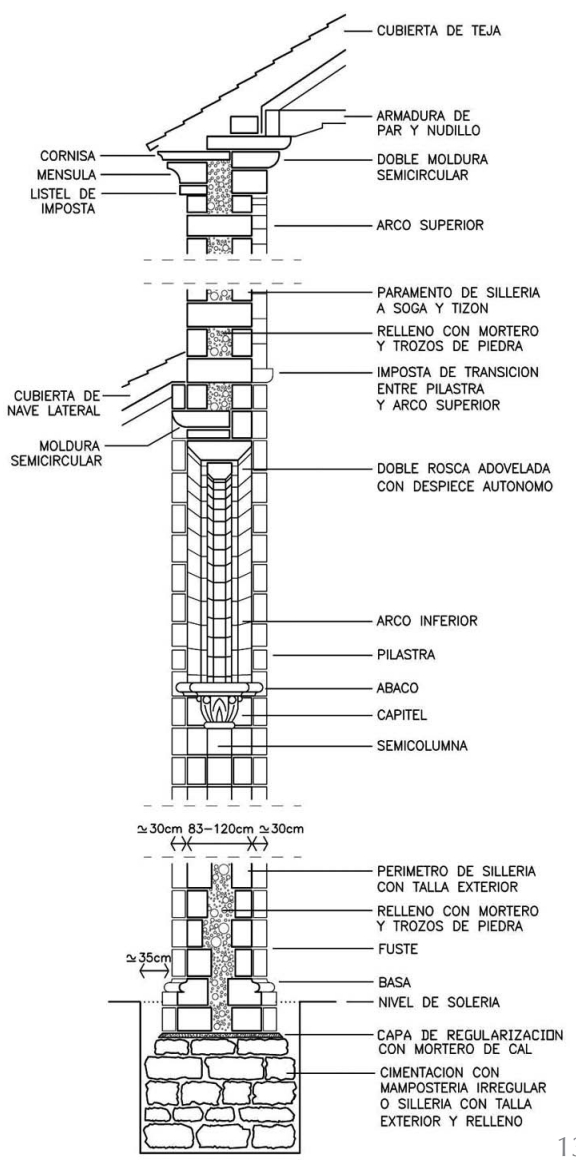


conjunto de escasa compacidad constituido por un mortero de cal con trozos de piedra y bolos (36); esta solución ahorraba material pétreo, evitaba el tallado de la cara interior de los sillares, y simplificaba el despiece del elemento (Figura 14). Como evidencian los propios paramentos, a ésta cáscara pétrea se traban las columnas y pilastras adosadas, macizas y despiezadas por hiladas horizontales coincidentes con las del núcleo; el aparejo utilizado evita la superposición de juntas, alternando las hiladas, y adoptando un esquema de macho-hembra recogido casi expresamente por Villard (37) (Figura 15 y Figura 9). La altura de las hiladas es a menudo heterogénea, entre 24 y $40 \mathrm{~cm}$., quizás porque, como documentan casos coetáneos (38), se establecería un rango de tolerancia dimensional para la extracción en cantera. Sin embargo esto también puede deberse a los formatos disponibles de expolio o en algunos edificios a las distintas reparaciones sufridas.

Las cimentaciones de estos pilares son escasas, constituidas por un macizo cuadrado aislado cuyas dimensiones apenas superan la sección del fuste. Se descomponen en una sillería de piezas más o menos irregulares, según el edificio, y si tienen talla, es únicamente al exterior; el conjunto se termina con una mortero de regularización. La cota del firme es bastante superficial, entre un metro y medio y dos, lo que ha motivado recalces desde antiguo; éstos están documentados en los casos de La Magdalena (39), San Pedro (40) o Santa Marina (41), y se han reiterado en distintos momentos del siglo XX.

Por último, distintos indicios en las fábricas permiten detectar que las arquerías frecuentemente se levantaban una vez concluida totalmente la cabecera, e incluso a veces, una vez conformado el propio perímetro mura de las naves. Así, las discontinuidades entre éstas y los ábsides son manifiestas en San Lorenzo, con una importante diferencia de anchura, o en el lienzo norte de La Magdalena. Incluso, en el caso de Santa Marina, es posible saber que el proceso de construcción de las arcadas avanzaría desde el hastial hacia la cabecera, como evidencia el apoyo de la sillería de la nave central en el arco toral de la capilla mayor, o las manifiestas adarajas existentes en el paramento norte (Figura 16). Esto, sin embargo, no implica que el replanteo in situ de la arquería, fijando pilares y luces a salvar, se hiciera también en este mismo orden. Contrariamente, el análisis dimensional y metrológico posteriormente expuesto trasluce que habitualmente el proceso era inverso, de la cabecera a los pies.

\section{TRAZADO, DIMENSIÓN Y MEDIDA DE ARCOS Y PILARES}

En el dibujo de la planta del edificio, la traça, residía lo sustancial del proyecto gótico, constituyendo según Cabezas (42) un modo autónomo y autosuficiente de pensar la arquitectura; posteriormente, para crecer el edificio, se irían concretando los diseños a medida que fueran necesarios. Este proceder, actualmente bien documentado, suponía que en el momento de levantar los pilares las luces de a salvar ya estaban prácticamente prefijadas, derivando de los criterios compositivos y organizativos de la planta. Concretamente, en los edificios estudiados, éstos son comunes y consisten en sencillas tramas ortogonales, posicionando los muros perimetrales por su cara interior y los pilares por su eje (43).

Por otro lado, en el análisis realizado no se aprecian criterios generales para el trazado y proporciones del conjunto de la arcada, aunque sí subyacen analogías para los pilares, por un lado, y para el trazado de los arcos por otro. El proceso de diseño, pues, parece estar secundando el propio proceso constructivo. Coherentemente con esto, se estudiarán independientemente los pilares y el sistema de arcos que apoya en ellos.

\subsection{Pilares}

En la sección de los pilares debe distinguirse entre el núcleo central, sensiblemente cuadrado, y las columnas y pilastras de sus lados. Los datos obtenidos para cada iglesia se reflejan en la Figura 17, incluyendo las propuestas de interpretación metrológica a partir del patrón dimensional previamente detectado en cada una. Tres edificios coinciden en el tener
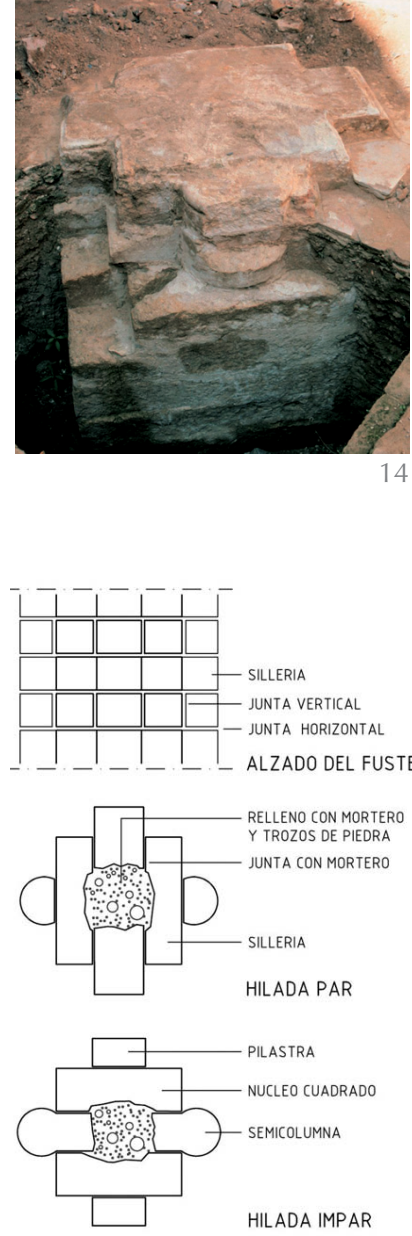

14. Pilar arruinado en Santiago (1988). Archivo de la Junta de Andalucía.

15. Despiece tipo del fuste de un pilar.

16. Nave central de Santa Marina: adarajas por interrupción de la construcción y unión con cabecera.

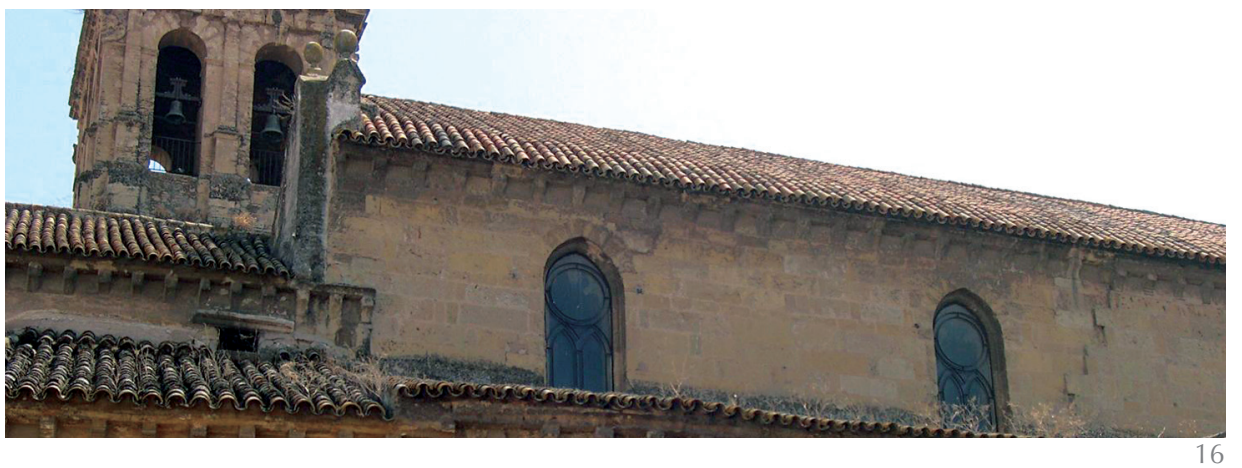


17. Dimensiones y análisis de parámetros del fuste del pilar (sección típica).

18. Despiece constructivo de arcada tipo de iglesia (S. Lorenzo), trazado de arcos y parámetros analizados.

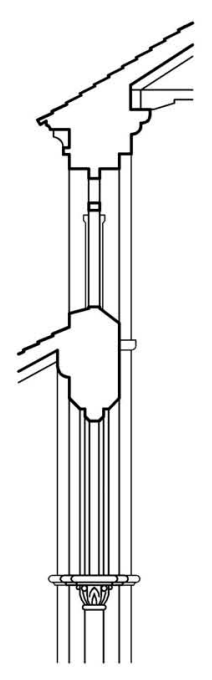

PATRÓN MÉTRICO

ALTURA $(H)$

ESBELTEZ

LUZ LIBRE / ESPESOR

S. LORENZO
$\begin{aligned} & P=83,59 \mathrm{~cm} \text { (vara) } \\ & H=655 \mathrm{~cm}\end{aligned}$
$\begin{array}{ll}\mathrm{ESB}=5,55 \\ \mathrm{LUZ} / \mathrm{ESP}=4,32\end{array}$

S. PEDRO

$P=83,59 \mathrm{~cm}$ (vara)

$\mathrm{H}=725 \mathrm{~cm}$

$\mathrm{ESB}=7,32$

LUZ / ESP $=5,41$
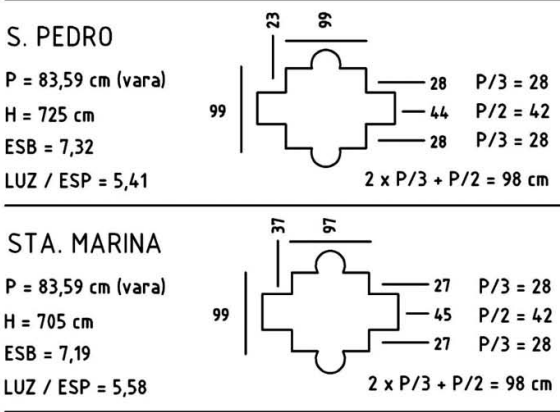

UZ $/ E S P=5,58$

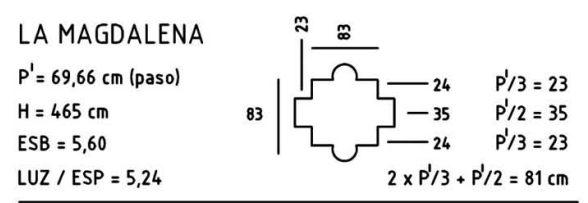

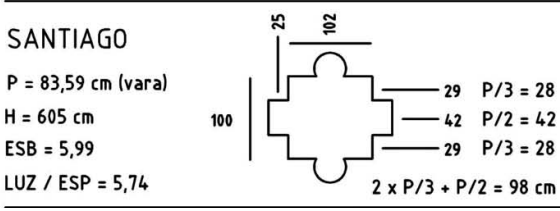

un mismo núcleo cuadrado, cuyo lado oscila entre 99 y $102 \mathrm{~cm}$, quedando claramente por debajo La Magdalena $(83 \mathrm{~cm}$.), y superando a todos ellos San Lorenzo $(120 \mathrm{~cm}$.). A estos núcleos cuadrados se adosan pilastras y columnas; éstas, secundando los esquemas de la época, empotran alrededor del tercio del diámetro, sin llegar nunca a la mitad.

Metrológicamente se advierten sólo dos tipos de núcleo cuadrado: aisladamente, el de San Lorenzo, cuyo lado es obtenido como una vez y media del patrón métrico (o tres medias varas burgalesas); y el de los otros cuatro casos, que se adapta al valor de media vara y dos pies, distribuido entre la anchura de la pilastra adosada (1/2 vara) y los dos espacios laterales restantes (un pie a cada lado, en vez de 1/2 vara como en el anterior tipo). En este grupo debe precisarse que Santa Marina, S. Pedro y Santiago aplican la vara burgalesa como patrón dimensional, y La Magdalena el submúltiplo del paso $(69,66 \mathrm{~cm}$.), aunque asumiendo el mismo esquema de proporciones.

Las alturas se gradúan en tres escalones dimensionales: el inferior, representado por $\mathrm{La}$ Magdalena, cuyos $465 \mathrm{~cm}$. no son fácilmente interpretables metrológicamente; uno intermedio constituido por Santiago $(605 \mathrm{~cm}$.) y San Lorenzo $(655 \mathrm{~cm}$. , u ocho varas burgalesas); y el mayor de alrededor de $709 \mathrm{~cm}$., generado por seis varas mayoradas por raíz de dos (Santa Marina, 705 cm.; San Pedro, $725 \mathrm{~cm}$.). Esta gradación no parece aleatoria, ya que en los cuerpos de naves de mayor longitud se le da también más altura a los soportes, evitando así que el espacio resulte demasiado horizontal. Sin embargo, para obtener esta mejora no se utilizan reglas estrictamente proporcionales, al mantenerse muchas de las secciones resistentes.

Esto aumenta otro de los parámetros analizados, la esbeltez, tomada como relación entre altura y espesor del núcleo cuadrado. La misma tiene dos rangos, el inferior entre 5,55-5,99, excesivamente prudente, y utilizado en tres edificios; y el superior 7,19-7,32, aplicado una vez más a los cuerpos de naves de mayor tamaño y longitud, Santa Marina y San Pedro. Por otro lado, en la relación entre la luz libre y el espesor del núcleo cuadrado, San Lorenzo $(4,32)$ se descuelga como el edificio más prudente, concentrándose los otros cuatro en la estrecha horquilla de 5,24-5,74.

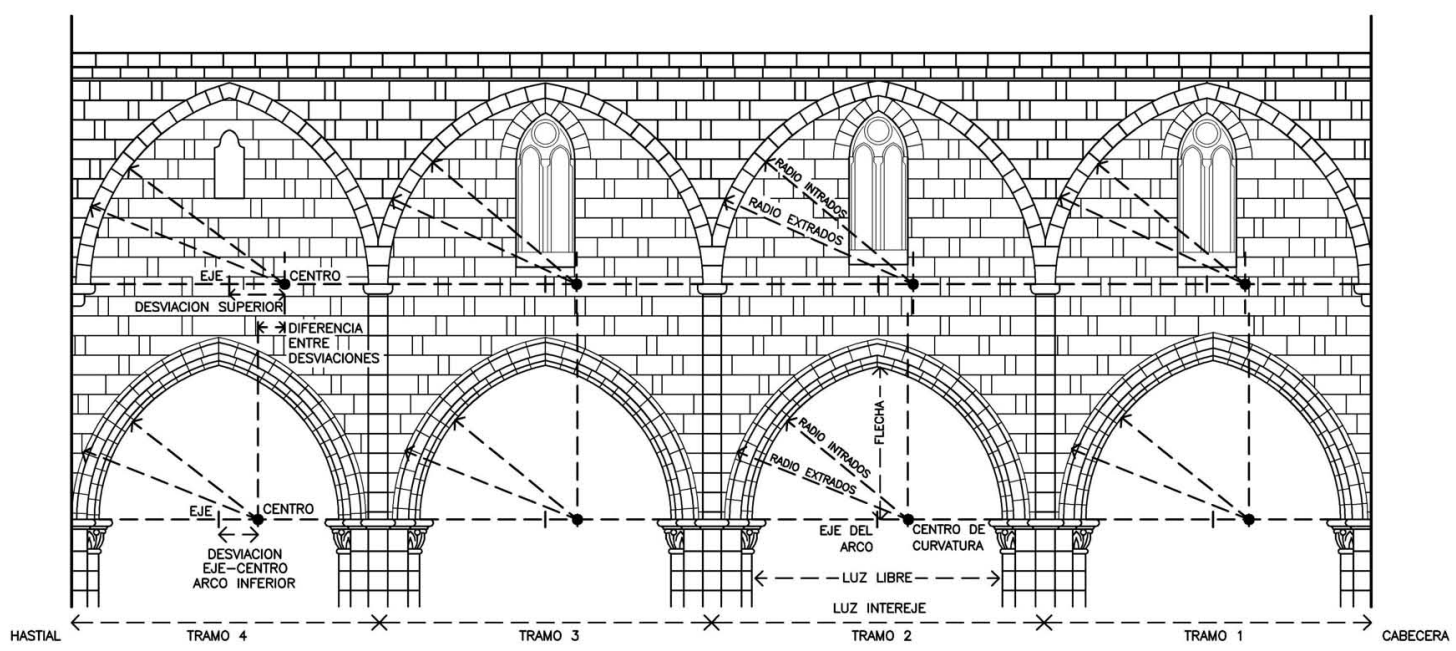


PARAMETROS DE ARCOS SUPERIOR E INFERIOR (centímetros)

\begin{tabular}{|c|c|c|c|c|c|c|c|}
\hline $\begin{array}{l}\text { EDIFICIO } \\
\text { PATRON METRICO }\end{array}$ & TRAMO & $\begin{array}{c}\text { LUZ } \\
\text { INTEREJE }\end{array}$ & $\begin{array}{l}\text { LUZ LIBRE } \\
\text { SUP. / INF. }\end{array}$ & $\begin{array}{l}\text { FLECHA } \\
\text { SUP. / INF. }\end{array}$ & $\begin{array}{l}\text { RADIO } \\
\text { EXTRADOS } \\
\text { SUP. / INF. }\end{array}$ & $\begin{array}{l}\text { RADIO } \\
\text { INTRADOS } \\
\text { SUP. / INF. }\end{array}$ & $\begin{array}{c}\text { DESVIACION } \\
\text { EJE-CENTRO ARCO } \\
\text { SUP. / INF. / DIFERENCIA }\end{array}$ \\
\hline S. LORENZO & 1 & 665 & $620 / 520$ & $380 / 325$ & $417 / 392$ & $387 / 333$ & $77 / 73 / 4$ \\
\hline \multirow[t]{4}{*}{$P=83,59 \mathrm{~cm}$ (vara) } & 2 & 679 & $641 / 511$ & $385 / 312$ & $421 / 377$ & $391 / 318$ & $71 / 62 / 9$ \\
\hline & 3 & 678 & $643 / 513$ & $383 / 315$ & $415 / 381$ & $385 / 322$ & $64 / 66 / 2$ \\
\hline & 4 & 625 & $567 / 490$ & $380 / 315$ & $426 / 384$ & $396 / 325$ & $113 / 80 / 33$ \\
\hline & MEDIA & 662 & $617 / 508$ & $382 / 317$ & $420 / 384$ & $390 / 325$ & $81 / 70 / 11$ \\
\hline \multicolumn{2}{|c|}{ REFERENTE METROLOGICO } & \multicolumn{2}{|c|}{$669(8 \times P)$} & & \multicolumn{3}{|c|}{$334(4 \times P)$} \\
\hline S. PEDRO & 1 & 670 & $640 / 552$ & $375 / 350$ & $412 / 399$ & $380 / 359$ & $60 / 83 / 23$ \\
\hline \multirow[t]{4}{*}{$P=83,59 \mathrm{~cm}$ (vara) } & 2 & 650 & $590 / 515$ & $370 / 340$ & $412 / 393$ & $380 / 353$ & $85 / 96 / 11$ \\
\hline & 3 & 685 & $645 / 560$ & $380 / 340$ & $417 / 386$ & $385 / 346$ & $63 / 66 / 3$ \\
\hline & 4 & 690 & $655 / 569$ & $380 / 340$ & $416 / 385$ & $384 / 345$ & $57 / 61 / 4$ \\
\hline & 5 & 625 & $550 / 485$ & $368 / 335$ & $415 / 393$ & $383 / 353$ & $108 / 113 / 5$ \\
\hline & MEDIA & 664 & $616 / 536$ & $375 / 341$ & $414 / 391$ & $383 / 351$ & $74 / 84 / 10$ \\
\hline \multicolumn{2}{|c|}{ REFERENTE METROLOGICO } & \multicolumn{2}{|c|}{$669(8 \times P)$} & & \multicolumn{3}{|c|}{$355(3 \times P \sqrt{2})$} \\
\hline STA. MARINA & 1 & 645 & $630 / 498$ & $460 / 350$ & $522 / 457$ & $493 / 384$ & $178 / 135 / 43$ \\
\hline \multirow[t]{5}{*}{$P=83,59 \mathrm{~cm}$ (vara) } & 2 & 760 & $723 / 600$ & $460 / 348$ & $502 / 407$ & $473 / 354$ & $112 / 54 / 58$ \\
\hline & 3 & 720 & $680 / 550$ & $462 / 360$ & $510 / 426$ & $481 / 373$ & $141 / 98 / 43$ \\
\hline & 4 & 740 & $705 / 590$ & $470 / 350$ & $519 / 408$ & $490 / 355$ & $138 / 60 / 78$ \\
\hline & 5 & 640 & $610 / 495$ & $459 / 345$ & $528 / 417$ & $499 / 364$ & $194 / 117 / 77$ \\
\hline & MEDIA & 701 & $670 / 547$ & $462 / 351$ & $516 / 419$ & $487 / 366$ & $153 / 93 / 60$ \\
\hline \multicolumn{2}{|c|}{ REFERENTE METROLOGICO } & \multicolumn{2}{|c|}{$709(6 \times P \sqrt{2})$} & & \multicolumn{3}{|c|}{$355(3 \times P \sqrt{2})$} \\
\hline LA MAGDALEN & A 1 & 562 & $-/ 415$ & $-/ 265$ & $-/ 313$ & $-/ 273$ & $-/ 66 /-$ \\
\hline \multirow[t]{3}{*}{$P^{\prime}=69,66 \mathrm{~cm}$ (paso) } & 2 & 547 & $-/ 417$ & $-/ 263$ & $-/ 310$ & $-/ 277$ & $-/ 62 /-$ \\
\hline & 3 & 530 & $-/ 402$ & $-/ 261$ & $-/ 310$ & $-/ 270$ & $-169 /-$ \\
\hline & 4 & 630 & $-/ 507$ & -1275 & -1325 & -1285 & $-/ 31 /-$ \\
\hline & MEDIA & 567 & $-/ 435$ & -1266 & $-/ 315$ & $-/ 275$ & $-/ 57 /-$ \\
\hline \multicolumn{2}{|c|}{ REFERENTE METROLOGICO } & \multicolumn{2}{|c|}{$558\left(8 \times P^{\prime}\right)$} & & \multicolumn{3}{|c|}{$279\left(4 \times P^{\prime}\right)$} \\
\hline SANTIAGO & 1 & 705 & $662 / 580$ & $410 / 354$ & $439 / 417$ & $411 / 362$ & $80 / 72 / 8$ \\
\hline \multirow{2}{*}{$P=83,59 \mathrm{~cm}$ (vara) } & 2 & 720 & $670 / 582$ & $408 / 353$ & $437 / 414$ & $409 / 359$ & $74 / 68 / 6$ \\
\hline & 3 & 717 & $670 / 577$ & $410 / 355$ & $441 / 418$ & $413 / 363$ & $78 / 74 / 4$ \\
\hline & MEDIA & 714 & $667 / 580$ & $409 / 354$ & $439 / 416$ & $411 / 361$ & $77 / 71 / 6$ \\
\hline \multicolumn{2}{|c|}{ REFERENTE METROLOGICO } & \multicolumn{2}{|c|}{$709(6 \times P \sqrt{2})$} & & \multicolumn{3}{|c|}{$355(3 \times P \sqrt{2})$} \\
\hline
\end{tabular}

\subsection{Sistemas de arcos superior $\mathrm{e}$ inferior}

El estudio de los arcos se realiza desde el conocimiento de su lógica constructiva, un planteamiento que pretende ser coherente con su génesis, evitando enfoques teóricos o especulativos sobre proporciones generales, trazados reguladores, etc. Los parámetros que caracterizan su trazado, dimensiones y geometría se recogen en las Figuras 18 y 19 , comprendiendo también el despiece constructivo de la arquería.

Las arcadas salvan tres rangos de luces intereje de pilares, determinadas en el trazado general de la planta. Sus valores medios son $567 \mathrm{~cm}$. en La Magdalena, 662 y 664 en San Lorenzo y San Pedro, respectivamente, y 701 y 714 en Santiago y Santa Marina.

No obstante, a nivel metrológico estamos tan sólo con dos tipos: aquel cuyas luces se obtienen como ocho veces el patrón métrico del edificio, aplicado a los tres primeros, y
19. Parámetros analizados en la arcadas: dimensiones absolutas y medias, e interpretación metrológica de las luces intereje de pilares y de los radios de curvatura del intradós de los arcos inferiores. 
así como la desviación de dichos éstos respecto del eje de simetría del arco.

Al margen de los aspectos cuantitativos, posteriormente comentados, es destacable la posición relativa de los centros obtenidos. Éstos constituyen puntos claramente accesibles por estar en el intradós, replanteándose con facilidad al mismo nivel que el arranque de los arcos. Además, en edificios como San Lorenzo, San Pedro y Santiago los centros del arco superior e inferior están prácticamente en la misma vertical, algo que es manifiestamente apreciable en el parámetro analizado de la desviación respecto del eje de simetría, y la diferencia entre los dos niveles. Este criterio sólo se transgrede en Santa Marina, y en La Magdalena no es comprobable por la pérdida del sistema de arcos superiores (Figura 5).

Las luces libres medidas en las arcadas tienen valores homogéneos, con oscilaciones inferiores a los $50 \mathrm{~cm}$.; se exceptuarían de esta uniformidad los tramos extremos, contiguos a cabecera y pies, principalmente éste último. Esto sugiere que las arquerías pudieron levantarse una vez formalizado el perímetro mural del edificio, teniéndose que hacer ajustes en el momento de su replanteo definitivo, posiblemente hecho desde la cabecera hacia los pies. Sólo así se explicaría que el último tramo sea casi siempre distinto, y salvo en La Magdalena, más corto que los anteriores. La reducción de la luz en arcos extremos suele compensarse con un aumento del radio de curvatura, para así alcanzar flechas similares al resto; serán, prácticamente, los únicos arcos claramente apuntados, ya que, salvo en Santa Marina, las formas se aproximan bastante al semicírculo, principalmente en los arcos superiores.

Salvo operaciones de ajuste como ésta, los radios de curvatura medidos en una misma arquería pueden considerarse prácticamente iguales. Los del intradós de los arcos inferiores debieron de modularse a partir del patrón métrico establecido para el edificio, secundando un proceder detectado en el gótico catalán (45). Así, en San Lorenzo y La Magdalena se adopta el valor de cuatro veces dicho patrón, que en el primer caso es la vara burgalesa y en el segundo pudo ser su submúltiplo del paso; en los otros tres casos este valor asciende hasta tres varas mayoradas por raíz de dos. Este criterio para la determinación del radio evidencia su autonomía respecto a la luz libre y la flecha del arco. Esto deja de lado otros procedimientos gráficos documentados en la época, basados en la división de la luz en partes iguales, tomando como radio las necesarias según el apuntamiento deseado para el arco (46).
Se podían así homogeneizar los arcos o anticipar la ejecución de cimbras y dovelas, todo ello al margen variaciones dimensionales en el replanteo y formalización de las luces entre apoyos, siempre que las mismas fueran moderadas. De hecho, en aras de la racionalidad y economía de la fábrica, se está utilizando el mismo radio de curvatura para salvar luces dentro de un rango, igualando los arcos del edificio lo más posible; de algún modo u otro, el constructor gótico sería consciente de que, en virtud de las relaciones geométricas subyacentes, esto no tenía una repercusión sustancial en la flecha obtenida.

En cambio, en los arcos superiores es más acentuada la voluntad de igualar las flechas, ya que sus claves prácticamente están en contacto con la cornisa superior que recibe la cubierta. Así, el apuntamiento de algunos de los arcos extremos más pequeños se incrementa todo lo necesario para obtener unas claves al mismo nivel. Salvo ajustes de este tipo, en San Lorenzo, San Pedro y Santiago los radios de curvatura del intradós prácticamente coinciden con los del extradós de la arcada inferior. Esto tiene una clara incidencia formal en el aspecto del alzado de la arquería; también supone, considerando que los centros están en la misma vertical, que el arco podría obtenerse por traslación del inferior, elevándolo. Y aunque la cimbra de éste no sería utilizable tal cual, bastaría con una adición perimetral de en torno a $50 \mathrm{~cm}$.

\section{CONCLUSIONES}

El sistema de arcadas diseñado en Córdoba atendió a la necesidad de edificios sencillos, ágiles de ejecución y económicos, integrándose adecuadamente en el conjunto arquitectónico. En este contexto, es destacable la habilidad para asumir y adaptar esquemas formales diversos, algunos de raigambre románica, y concebidos para abovedamientos en vez de para cubiertas lígneas. Esto conduce a simplificar los soportes y a practicar distintas adaptaciones a los arcos, partiendo de un esquema de muro armado, ya utilizado por ejemplo en el templo cisterciense de Poblet (siglo XII). Una de las operaciones más características consistió en la redefinición del originario trazado semicircular, sustituido por el apuntado; éste además, dentro de un mismo edificio, tiende a mantener invariables los radios de curvatura de los arcos, consiguiendo una optimización del proceso constructivo por el reaprovechamiento de las cimbras y la estandarización de dovelas. Constructivamente se asumen soluciones comprobadas, formalizándose arcadas mediante una sillería perimetral y relleno interior con una mampostería pobre. En ellas se 
combinan grandes sillares de acarreo islámicos, que determinarían el aparejo a soga y tizón, con la talla de elementos específicos del catálogo formal gótico.

El diseño de las arquerías parte de luces preestablecidas por el diseño general de la planta, que fija, basándose en sus propios criterios compositivos, la posición de los pilares. Posteriormente, establecidos sus espesores, y una vez levantados, se abordaría el sistema superior de arcos y muro armado. En estos arcos, el principal parámetro a fijar por el maestro era el radio de curvatura, y del que derivaban la flecha y las demás proporciones generales; es sintomático, en este sentido, que el radio del intradós del arco inferior sea la única dimensión del sistema de arcadas que tiene una nítida interpretación metrológica a partir del patrón métrico de cada edificio.

La coincidencia de los edificios en muchos de los parámetros estudiados evidencia el recurso a reglas preestablecidas, hoy difíciles de precisar, y que conducían a secciones consideradas válidas dentro de un cierto rango de luces y cargas, sancionadas por la experiencia. Puede que esto esté reaprovechando un cierto sobredimensionamiento estructural, consciente o no, pero la manera de operar es muy eficaz constructivamente, demostrando además una gran confianza en los conocimientos del oficio. Esto contrasta en cierta manera con el mayor determinismo subyacente en los tratados del gótico tardío, cuyas reglas prácticamente establecían proyectos proporcionales. Incluso, a medida que el edificio va aumentando de tamaño, el constructor parece atreverse a más: Santa Marina, con largas arquerías y luces grandes, tiene arcos más apuntados, pilares más esbeltos o una mayor relación luz libre/espesor de las secciones resistentes.

Los constructores cordobeses, posiblemente maestros de segunda fila, no estarían capacitados para abordar las grandes fábricas de las catedrales y templos conventuales de la meseta. Sin embargo, poniendo a prueba sus conocimientos, las primeras iglesias de Córdoba intentarán secundar la sensibilidad del incipiente gótico hispano, ganando altura para mejorar los pesados edificios románicos y cistercienses. Con el tiempo, en el gótico andaluz se iría mucho más allá, demostrando el dominio de los maestros de los aspectos verdaderamente esenciales del diseño estructural de esta arquitectura.

\section{AGRADECIMIENTOS}

Se agradecen las facilidades prestadas para el estudio de la documentación del Archivo de la Delegación de Cultura en Córdoba de la Junta de Andalucía. Departamento de Protección del Patrimonio Histórico (autorización 28/8/00, ref. DPI/jvv/tv).

\section{BIBLIOGRAFÍA}

(1) Gómez de Cózar, J. C. y Benítez Bodes, R. M.: "Las soluciones inconclusas de las cubiertas de los templos medievales del Reino de Sevilla, España", Informes de la Construcción, vol. 60, n 509 (2008), pp. 57-67. doi: 10.3989/ic.2008.v60.i509.591.

(2) Blanco Roldán, R.: "Cubiertas de madera de las iglesias fernandinas de Córdoba", Informes de la Construcción, vol. 59, no 507 (2007), pp. 33-41. doi: 10.3989/ic.2007.v59.i507.530.

(3) García Ortega, A. J.: "Diseño y construcción de muros en el primer gótico cordobés", Informes de la Construcción, vol. 61, no 516 (2009), pp. 37-52. doi: 10.3989/ic.09.027.

(4) García Ortega, A. J.: "Mecanismos de proyecto medievales. El caso cordobés a partir de sus parroquias", Ra, no 5 (2003), pp. 3-12.

(5) Heyman, J.: Teoría, historia y restauración de Estructuras de fábrica. Instituto Juan de Herrera. E.T.S. Arquitectura de Madrid. Madrid, 1995, p. 1.

(6) Escrig Pallarés, F.: Las grandes estructuras de los edificios históricos: desde la antigüedad hasta el gótico, p. 130, Instituto Universitario de Ciencias de la Construcción, Sevilla, 1997.

(7) Heyman, J.: "Beauvais Cathedral", Transactions of the Newcomen Society, 40 (1967/1968), pp. $15-35$.

(8) Ruiz de la Rosa, J. A.: Traza y simetría de la Arquitectura, Universidad de Sevilla, Sevilla, 1987, pp. 193-259.

(9) Bechmann, R.: Villard de Honnecourt. La pensée technique au XIII siècle et sa communication, Picard, Paris, 1993, pp. 53 y 70.

(10) Lechler, L.: Unterweisung, Leipzig, [1516] 1856, fol. 44.

(11) De Sopranis Favraud, F. S.: "Las medidas castellanas en las reglas de trazado", Revista Nacional de Arquitectura, $\mathrm{n}^{\circ}$ 49-50 (1946), pp. 15-8.

(12) Lechler, L.: Unterweisung, Leipzig, [1516] 1856, fol. 51v.

(13) García Ortega, A. J.: "Mecanismos de proyecto medievales. El caso cordobés a partir de sus parroquias", Ra, no 5 (2003), pp. 10-11.

(14) Huerta, S. y Aroca, R.: "Cúpulas de fábrica. Un estudio de sus dimensiones y semejanzas", Ingeniería Civil, 75 (1990), pp. 109-123.

(15) Heyman, J.: "The Stone Skeleton", International journal of solids and Structures, 2 (1966), pp. 249-279. 
(16) Cortón de las Heras, M. T.: La construcción de la Catedral de Segovia (1525-1607), Caja de Ahorros y Monte de Piedad de Segovia. Segovia, 1997, p. 251.

(17) Gómez de Cózar, J. C.: Cul de lampe: Adaptación y disolución del gótico en el Reino de Sevilla, Universidad de Sevilla, Sevilla, 2009.

(18) Huerta, S.: Arcos, bóvedas y cúpulas. Geometría y equilibrio en el cálculo tradicional de estructuras de fábrica, Instituto Juan de Herrera, Madrid, 2004, p. 477.

(19) Huerta, S.: Arcos, bóvedas y cúpulas. Geometría y equilibrio en el cálculo tradicional de estructuras de fábrica, Instituto Juan de Herrera, Madrid, 2004, pp. 77-79 y 126-129.

(20) Carrasco Hortal, J. y Millán Gómez, A.: La estructura gótica catalana: Sobre Ios conceptos de medida y espacio. El problema de la forma de la cubierta, Fecsa-Endesa, Barcelona, 2006, pp. 17-19.

(21) Villard d'Hônnecourt: Cuaderno de notas (ms. fr 19093-Biblioteca Nacional, París).

(22) Bechmann, R.: "Los dibujos técnicos del Cuaderno de Villard de Honnecourt", en ErlandeBrandenbur, A. et al., Villard de Honnecourt. Cuaderno, siglo XIII, pp. 45-58, Akal, Madrid, 2001. También, Bechmann, R.: Villard de Honnecourt. "La pensée technique au XIII siècle et sa communication", Picard, Paris, 1993, pp. 205-230.

(23) Rabasa Díaz, E.: Forma y construcción en piedra. De la cantería medieval a la estereotomía del siglo XIX, Akal, Madrid, 2000, p. 63.

(24) Vorsevi, S. A.: Estudio de la iglesia de S. Pedro de Córdoba (inédito), Sevilla, 1991, pp. 1516. También, Barrios-Neira, J. et al.: "Contribución al estudio litológico de los materiales empleados en monumentos de Córdoba de distintas épocas", Arqueología de la Arquitectura, 2 (2003), pp. 47-53.

(25) Jiménez Martín, A.: "La primera cantera andalusí", Actas del Tercer Congreso Nacional de Historia de la construcción, vol. II, pp. 549-555, Sevilla, 2000.

(26) Rondellet, J. B.: Traite théorique et practique de IÁrt de Bâtir, Paris, 1804.

(27) Vázquez Lesmes, J. R.: "Monasterio y Colegiata de San Hipólito de Córdoba (1343-1399)", Actas del I Congreso de Historia de Andalucía, vol. 1, pp. 147-61, Córdoba, 1978.

(28) Marfil Ruiz, P.: Intervención arqueológica de urgencia. Iglesia de San Pedro (inédito), Córdoba, 1996.

(29) Marfil Ruiz, P.: Intervención arqueológica de urgencia en la Iglesia de La Magdalena (inédito), Córdoba, 1996.

(30) Córdoba de la Llave, R.: "Aportaciones arqueológicas al conocimiento de técnicas de construcción de la Córdoba bajomedieval", Actas del Primer Congreso Nacional de Historia de la Construcción, pp. 151-158, Madrid, 1996.

(31) Cabrera Ponce de León, A. y Rodríguez López, O.: "Rehabilitación de la iglesia de Santiago de Córdoba", Cuadernos de intervención en el Patrimonio Histórico, no 1 (1990).

(32) Lara de la Peña, C. y Sanz Cabrera, J.: Proyecto de restauración de la iglesia de La Magdalena (inédito), Consejería de Cultura y Medio Ambiente, Junta de Andalucía, Córdoba, 1991, p. 11. También, Marfil Ruiz, P.: Intervención arqueológica de urgencia en la Iglesia de La Magdalena (inédito), p.1. Córdoba, 1996.

(33) Ramírez Laguna, A.: Obras de emergencia en la iglesia de S. Pedro de Córdoba (informe técnico inédito), Córdoba, 1993.

(34) Branner, R.: "Villard de Honnecourt, Archimedes, and Chartres", Journal of the Society of Architectural Historians, vol. 19, no 3 (1960), pp. 91-96. También, Rabasa Díaz, E.: "Forma y construcción en piedra. De la cantería medieval a la estereotomía del siglo XIX", pp. 4345, Akal, Madrid, 2000.

(35) García Ortega, A. J.: "Diseño y construcción de muros en el primer gótico cordobés", Informes de la Construcción, vol. 61, no 516 (2009), pp. 43-47. doi: 10.3989/ic.09.027.

(36) Vorsevi, S. A.: Estudio de la iglesia de S. Pedro de Córdoba (inédito), Sevilla, 1991, pp. 14 y 42.

(37) Villard d'Hônnecourt: Cuaderno de notas, fol. 15v y 32 (ms. fr 19093-Biblioteca Nacional, París).

(38) Ginovart, J. L.: "La Scientia vero de ingeniis. El concepto de homogeneidad del material versus resistencia en los pilares de una catedral gótica", Actas del VI Congreso Nacional de Historia de la Construcción, pp. 753-761, Valencia, 2009.

(39) Marfil Ruiz, P.: Intervención arqueológica de urgencia en la Iglesia de La Magdalena (inédito), Córdoba, 1996, p. 7.

(40) Ramírez Laguna, A.: Proyecto de obras de restauración en la iglesia de S. Pedro de Córdoba (inédito), Junta de Andalucía, Consejería de Cultura, Córdoba, 1994.

(41) Cano Fernández, A.: "Intervención arqueológica preventiva. Control arqueológico de movimiento de tierras en la iglesia de Santa Marina de Córdoba", Anuario Arqueológico de Andalucía, vol. III, (2004), pp. 245-246.

(42) Cabezas, L.: "Ichnographia, la fundación de la arquitectura", EGA, no 2 (1994), pp. 82-94.

(43) García Ortega, A. J.: "Mecanismos de proyecto medievales. El caso cordobés a partir de sus parroquias", Ra, no 5 (2003), pp. 11-12.

(44) Huerta, S.: "Las reglas estructurales del gótico tardío alemán", Actas del V Congreso Nacional de Historia de la Construcción, pp. 519-532, Burgos, 2007.

(45) Carrasco Hortal, J. y Millán Gómez, A.: La estructura gótica..., p. 15.

(46) Branner, R.: "Villard de Honnecourt, Archimedes, and Chartres", Journal of the Society of Architectural Historians, vol. 19, n 3 (1960), pp. 93-96. 